\title{
Bisexuality and /s/ production
}

\section{Chloe Willis*}

\begin{abstract}
The belief that there are systematic differences in speech production as a function of sexual orientation has inspired a vast body of linguistic research investigating the acoustic correlates of sounding queer. Although gay-sounding voices and to a lesser extent lesbian-sounding voices are well represented in this literature, bisexuality is conspicuously absent. The current study addresses this gap through an acoustic analysis of bisexual English speakers' read speech vis-à-vis lesbian, gay, and straight speakers, specifically attending to three measures of the voiceless alveolar fricative /s/: center of gravity, skew, and duration. A qualitative analysis of post-test participant information surveys contextualizes the statistical results. The study finds that bisexual women and men do not pattern consistently with lesbian, gay, or straight speakers, or even with each other. The results call into question the common methodological practice of grouping bisexual speakers with lesbian and gay speakers a priori and underscore the importance of intersectionality, gender normativity, and ideology in sociophonetic studies of sexuality and the voice.
\end{abstract}

Keywords. bisexuality; fricatives; language, gender, and sexuality; sociophonetics

1. Introduction. Gaudio's (1994) influential work on the pitch properties of gay and straight men's speech inspired numerous similar sociophonetic studies investigating the acoustic correlates of sounding queer. Many of these studies focus exclusively on gay men or sounding gay (e.g., Smyth, Jacobs \& Rogers 2003, Campbell-Kibler 2011), whereas relatively few studies focus on sounding lesbian (e.g., Van Borsel et al. 2013, Barron-Lutzross 2015). There are no sociophonetic studies centering bisexual speakers to my knowledge, though see Thorne (2013) for an ethnographic study. However, some studies on queer-sounding voices include a small number of bisexual participants (e.g., Pierrehumbert et al. 2004, Munson et al. 2006a, 2006b). In such cases, bisexual speakers are usually categorized with lesbian and gay speakers. While studies such as the work by Pierrehumbert and colleagues (2004) provide empirical justification for categorizing bisexual speakers with lesbian and gay speakers, many do not. The assumption that bisexual speakers will pattern with lesbian and gay speakers is made a priori. The findings reported here, however, trouble this assumption. All of this to say that, while much is known about sexuality and the voice, we cannot conclude that sexuality has acoustic correlates that go beyond ideologies of lesbian or gay and straight difference at this point.

Bisexuality makes important theoretical contributions to how the intersection between gender and sexuality is understood. Zimman (2013) points out that the intersection between gender and sexuality is often left implicit in sociophonetic studies, rendering the theorization of the interplay between the two incomplete (though see Munson et al. 2006a:234). Most experimental sociophonetic studies of sexuality and the voice are designed such that participants are catego-

\footnotetext{
* I would like to thank Lal Zimman and Mary Bucholtz for their continuous support of this project. I am also grateful to my participants, without whom this study would not have been possible. Special thanks to LSA 2021 attendees and fellow panelists for their invaluable questions and feedback. Sincere thanks to my fellow UCSB Linguistics graduate students who provided feedback on this paper: Julien Boulton, Jazmine Exford, Ryan Lai, Giorgia Troiani, and Albert Ventayol-Boada. Author: Chloe Willis, University of California, Santa Barbara

(chloemwillis@ucsb.edu).
} 
rized as straight or queer and results are interpreted as deviance from the straight norm. In other words, participants are positioned as normative or straight on the one hand and as queer or nonnormative on the other. When bisexual speakers are included in these studies, they are placed in the queer or LGB category. However, this non-normative positioning does not necessarily reflect how bisexual people experience the intersection between gender, sexuality, and normativity in daily life. The intersection between gender and sexuality and its interplay with normativity shifts between contexts for many bisexual people. Bisexual people in different-gender relationships are often perceived as normative, in terms of both gender and sexuality. In contrast, bisexual people in same-gender relationships are typically not perceived as normative for sexuality, which has implications for the perception of their gender. Of course, there are bisexual people who are perceived as non-normative regardless of the gender of their partner on the basis of their own gender presentation or other indexes of sexuality. These situations are meant to be heuristic rather than an exhaustive description of bisexual people's experiences. The point is that the potential fluidity and dynamic nature of gender and sexuality is particularly salient for bisexual people and that their experiences are not adequately accounted for by the most common experimental designs. In short, bisexuality troubles the underlying ideologies of gender, sexuality, and normativity that are left implicit in many studies of sexuality and the voice.

2. Literature on sexuality and the voice. A variety of potential acoustic correlates of sounding gay or sounding lesbian have been investigated over the years. The most thoroughly analyzed feature is pitch or F0 (e.g., Gaudio 1994, Smyth et al. 2003, Levon 2011, Van Borsel et al. 2013), although vowels (e.g., Linville 1998, Pierrehumbert et al. 2004, Rendall et al. 2008, Zimman 2013) and other fricatives, like / $/$ / (e.g., Munson et al. 2006a), have also been examined. The results of these studies have been inconsistent and occasionally even contradictory. For example, Waksler (2001) reports no significant differences in pitch or pitch variability between lesbian and straight women, whereas Van Borsel and colleagues (2013) find that lesbian women produce significantly lower mean F0 and fewer pitch fluctuations compared to straight women.

Analyses of $/ \mathrm{s} /$, on the other hand, have produced relatively consistent results (Zimman 2013). Several perception studies have found that variation in $/ \mathrm{s} / \mathrm{is}$ a particularly salient cue when listeners make judgements about sexuality in the North American, English-speaking context (e.g., Munson et al. 2006b, Levon 2007, Campbell-Kibler 2011). The results of production studies are slightly less stable, but overall findings indicate a correlation between /s/ production and sexual orientation, especially for men. Multiple studies report significant differences in how gay and straight men produce /s/ with respect to center of gravity (e.g., Munson et al. 2006b, Zimman 2013, Hazenberg 2016), skew (e.g., Munson et al. 2006a,b), and duration (e.g., Crist 1997, Linville 1998). Results are less consistent when comparing queer and straight women, but Hazenberg (2016) and Munson and colleagues (2006a) report significant differences in /s/ center of gravity between these two groups, more specifically that queer women produce /s/ with a lower center of gravity relative to straight women. ${ }^{1}$ In short, evidence suggests that an analysis of $/ \mathrm{s} /$ is an appropriate starting point for incorporating bisexuality into the literature.

\footnotetext{
${ }^{1}$ Hazenberg (2016) describes their participants as cisgender lesbian women or queer cisgender women, whereas Munson and colleagues (2006a) group lesbian and bisexual women together, such that the umbrella term reading of queer is fitting.
} 


\section{Methodology.}

3.1. PARTICIPANTS. Participants were 27 graduate and undergraduate students at the University of California, Santa Barbara. There were 5 speakers in each group, except for bisexual men; only two eligible bisexual men participated (Table 1). All participants identified as cisgender, were native English speakers, and were between 18 and 30 years old. Exploratory t-tests indicated that the gay men were significantly older than the other groups of men in this study $(t=1.79, p=$ 0.03 ), but there was no significant difference between the bisexual women and men and the other groups of women and men. Most speakers identified as white $(\mathrm{n}=15)$, but Latinx $(\mathrm{n}=5)$, Asian $(n=3)$, and mixed race $(n=4)$ speakers were also represented. The vast majority of participants identified one or more locations the US as their place(s) of origin $(n=23)$, with California being particularly well represented. Two participants reported locations in the US and Europe as their places of origin and one participant identified India as their place of origin.

\begin{tabular}{|c|c|c|c|c|c|}
\hline Group & $\mathbf{n}$ & Mean Age & Age Range & Race/Ethnicity & $\begin{array}{l}\text { Place of } \\
\text { Origin }\end{array}$ \\
\hline $\begin{array}{l}\text { Bisexual } \\
\text { women }\end{array}$ & 5 & 21 & $18-26$ & $\begin{array}{l}1 \text { Latinx/PI } \\
4 \text { white }\end{array}$ & US \\
\hline Bisexual men & 2 & 19 & $18-19$ & $\begin{array}{l}\text { 1 Latinx } \\
1 \text { white }\end{array}$ & US \\
\hline $\begin{array}{l}\text { Lesbian } \\
\text { women }\end{array}$ & 5 & 21 & $19-26$ & $\begin{array}{l}\text { 1 Latinx/white } \\
3 \text { white } \\
1 \text { white/Jewish }\end{array}$ & $\begin{array}{l}3 \mathrm{US} \\
2 \mathrm{US} \& \mathrm{Eu}- \\
\text { rope }\end{array}$ \\
\hline Gay men & 5 & 25 & $18-30$ & $\begin{array}{l}1 \text { Asian } \\
1 \text { Latinx/white } \\
3 \text { white }\end{array}$ & $\begin{array}{l}4 \text { US } \\
1 \text { India }\end{array}$ \\
\hline $\begin{array}{l}\text { Straight } \\
\text { women }\end{array}$ & 5 & 19 & $18-20$ & $\begin{array}{l}2 \text { Asian } \\
1 \text { Latinx } \\
2 \text { white }\end{array}$ & US \\
\hline Straight men & 5 & 19 & $18-20$ & $\begin{array}{l}3 \text { Latinx } \\
2 \text { white }\end{array}$ & US \\
\hline
\end{tabular}

Table 1. Participant information

3.2. STIMULI. Participants were recorded reading the Rainbow Passage (Fairbanks 1960), a phonetically balanced scientific passage about rainbows, as well as a list of 240 phonetically balanced sentences (Rothauser 1969). Speakers recorded the passage first and the sentences second. They were instructed to read the passage and all sentences twice only and to say the stimuli as naturally as possible. The analysis in this paper draws only from participants' first reading of the passage.

3.3. PROCEDURE. Participants were recorded in a sound-attenuated booth using Audacity (Audacity Team 2019). Recordings were sampled at a $44.1 \mathrm{kHz}$ rate with 16-bit quantization using either a Blue Snowball iCE USB Condenser microphone, a Blue Yeti USB microphone, or an AKG C 3000 B microphone. I impressionistically noticed no significant difference in audio quality between the three microphones.

During the informed consent process, speakers were told that they were participating in a two-part study on LGBQ and allied voices in California. They were told that they would be further debriefed on how their data would be used after recording was completed and that they 
would have the opportunity to withdraw consent and destroy their data at that time. After obtaining their initial consent, participants filled out a pre-test survey asking for personal information such as age, gender, sexuality, race/ethnicity, languages spoken, and so forth. When they finished recording, speakers filled out a post-test survey asking them about their gender stereotypicality and romantic partner preferences. Finally, participants were debriefed on how I intended to use their recordings and were reminded of their right to withdraw consent. None opted to do so.

3.4. ANALYSIS. Participants' first readings of the Rainbow Passage (Fairbanks 1960) were transcribed in Praat (Boersma 2011) and word-initial tokens of /s/ were extracted using a Python script. The script generated measurements for center of gravity, skew, kurtosis, and standard deviation. Tokens in the word STRIKE and the phrase FRIENDS SAY were discarded due to their phonological context. Specifically, /s/ retraction in /st./ clusters in words such as STRIKE is well documented (e.g., Shapiro 1995) and there is a tendency for the final /z/ in 'friends' to blend with the initial /s/ in 'say', making the token difficult to segment consistently. Disfluencies and tokens judged to contain periodicity were also discarded, leaving mean of 13.78 tokens per person and 372 tokens total. During this process I also manually checked measurements that were atypical: tokens in which the center of gravity was lower than $4 \mathrm{kHz}$ or higher than $8.5 \mathrm{kHz}$ and tokens in which the skew was less than -2 or more than 2 . All measurements were checked manually for tokens flagged as atypical. Duration was also hand measured for every token when I looked for periodicity.

3.5. STATISTICAL METHODOLOGY. Once the data was processed, I fit a linear mixed effects regression model for each dependent variable: center of gravity, skew, and duration. Models were fit using the lmer function from the lmerTest package in R (R Core Team 2019). SPEAKER and WORD were included as random effects with varying intercepts in each of the models. For model selection, I used the drop1 function from the lme4 package to select for the model with the best fit. The anova function from base $\mathrm{R}$ was used to determine the significance of the main effects. Finally, post-hoc pairwise comparisons were calculated using the relevel function from base $\mathrm{R}$ in order to capture the differences between all six groups. The Bonferroni method was used to compensate for evaluating the models multiple times, up to five times in the case of the center of gravity model.

It is pertinent to clarify at this point why I will report both Bonferroni-corrected significance values and uncorrected values in this paper. The first reason is a matter of convention: adjustments like the Bonferroni correction are not used consistently in experimental studies of sexuality and the voice, so it is not unusual to report unadjusted results. The second reason is a matter of the correction itself. The Bonferroni method is known for being intolerant of Type I errors; it can fail to detect true differences and is potentially overly conservative (Lee \& Lee 2018:237). Given these two points, I believe it is appropriate to report both sets of values, keeping in mind that the corrected values are held to a more rigorous standard.

\section{Statistical results.}

4.1. CENTER OF GRAVITY MODEL. Center of gravity (COG) measurements $(n=372)$ were subjected to a linear mixed-effects regression model. The model selection process indicated that the maximal model with GENDER, SEXUALITY and their interaction was the best fit. GENDER was a significant main effect, such that women generally produced /s/ with a higher COG than men $\left(\chi^{2}(1)=5.9, p=0.01\right)$. The interaction GENDER*SEXUALITY was also a significant main effect $\left(\chi^{2}(1)=9.5, p<0.01\right)$ (Figure 1). SEXUALITY was not a significant main effect, but 
could not be removed from the model due to its participation in a significant interaction. The fixed effects explained about $29 \%$ of the variance $(\mathrm{R} 2 \mathrm{~m}=0.29)$ and the random effects explained about $38 \%$ of the variance $(\mathrm{R} 2 \mathrm{c}=0.68)$. The random effect SPEAKER explained 6.6 times more variance than the random effect WORD.

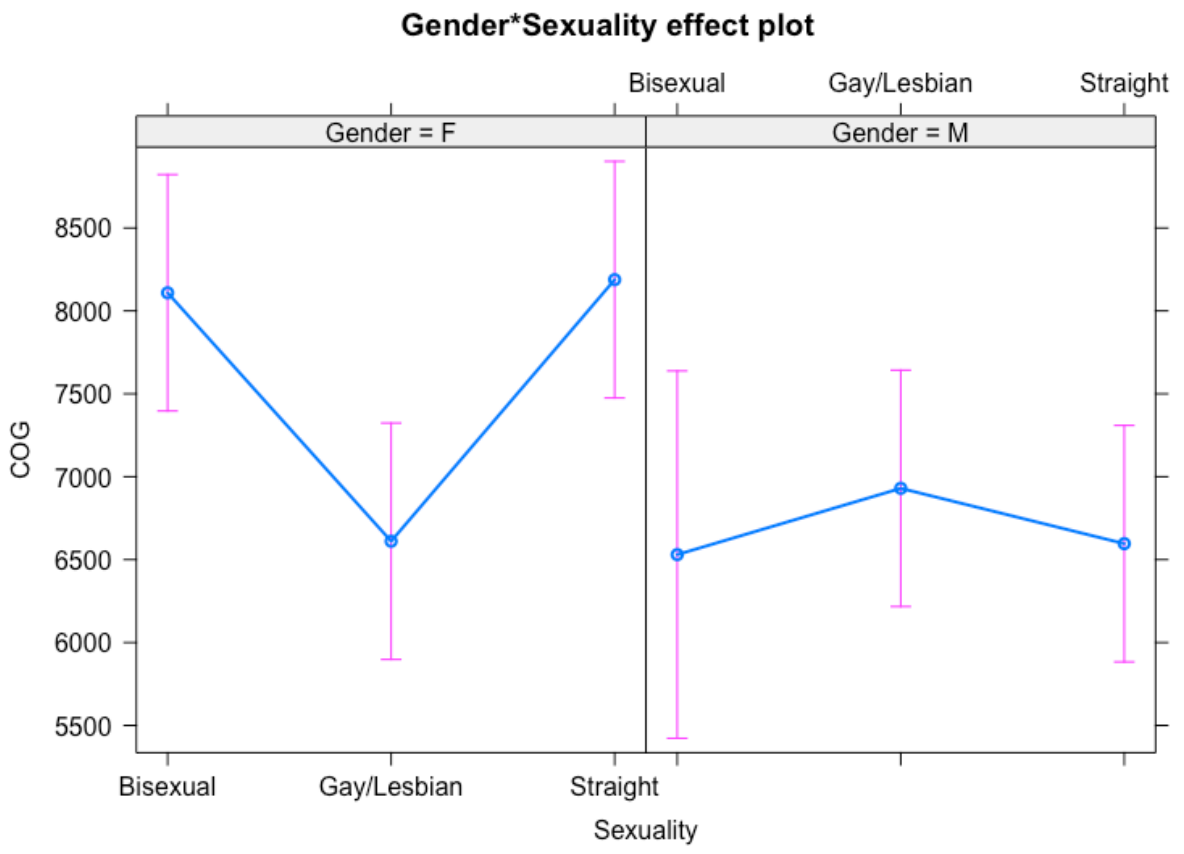

Figure 1. COG model effects plot

Among the women in this study, straight women produced /s/ with the highest estimated COG $(8288 \mathrm{~Hz})$, followed by bisexual women $(8109 \mathrm{~Hz})$, and then lesbian women $(6711 \mathrm{~Hz})$ (Table 2, Figure 1). The straight and bisexual women in this sample produced COG estimates that fell on the higher end of the expected range for women $(6.4-8.5 \mathrm{kHz})$, whereas lesbian women's COG estimates were on the lower end (Zimman 2017).

\begin{tabular}{|l|l|l|l|l|l|}
\hline Fixed effects & Estimate & Std. error & df & t value & Pr(>|t) \\
\hline $\begin{array}{l}\text { Intercept } \\
\text { (bisexual women) }\end{array}$ & 8109.01 & 362.54 & 23.26 & 22.367 & $<2 \mathrm{e}-16^{* * *}$ \\
\hline $\begin{array}{l}\text { Gender:M } \\
\text { (bisexual men) }\end{array}$ & -1578.87 & 658.73 & 20.91 & -2.397 & $0.026^{*}$ \\
\hline $\begin{array}{l}\text { Sexuality:Lesbian/gay } \\
\text { (lesbian women) }\end{array}$ & -1498.13 & 498.14 & 20.94 & -3.007 & $0.007 * *$ \\
\hline $\begin{array}{l}\text { Sexuality:Straight } \\
\text { (straight women) }\end{array}$ & 79.11 & 498.29 & 20.97 & 0.159 & 0.875 \\
\hline $\begin{array}{l}\text { Gender:M, Sexuali- } \\
\text { ty:Lesbian/gay } \\
\text { (gay men) }\end{array}$ & 1897.97 & 825.87 & 20.92 & 2.298 & $0.032 *$ \\
\hline $\begin{array}{l}\text { Gender:M, Sexuali- } \\
\text { ty:Straight } \\
\text { (straight men) }\end{array}$ & -12.85 & 825.97 & 20.93 & -0.016 & 0.988 \\
\hline
\end{tabular}

Table 2. COG model coefficients table 
As for the men in the study, gay men produced the highest estimated COG $(6930 \mathrm{~Hz})$, followed by straight men $(6696 \mathrm{~Hz})$, and then bisexual men $(6630 \mathrm{~Hz})($ Table 2, Figure 1). The estimate for gay men is on the higher end of expected COG values for men, but is still within the range considered typical (4-7 kHz) (Zimman 2017). Bisexual men's and straight men's COG estimates are well within the expected range.

In the initial evaluation of the model (Table 2), a significant difference was found between bisexual women and lesbian women, such that bisexual women produced /s/ with a higher COG than lesbian women $(\mathrm{p}<0.01)$. A significant difference between bisexual women and bisexual men was also found, such that bisexual women produced /s/ with a higher COG than bisexual men $(p<0.05)$. Similarly, a significant difference between bisexual women and gay men was found, such that bisexual women produced $/ \mathrm{s} /$ with a higher COG than gay men $(\mathrm{p}<0.05)$. There were no significant differences between bisexual women and straight women or straight men. 4.2. COG POST-HOC PAIRWISE COMPARISONS. The model was releveled four times in order to examine the full set of pairwise comparisons for each group (five evaluations overall). Comparing within gender but across sexuality (Table 3), significant differences between bisexual women and lesbian women $(\mathrm{p}<0.01)$ as well as lesbian women and straight women $(\mathrm{p}<0.01)$ were maintained before and after the correction. No significant differences in COG were found between the groups of men.

\begin{tabular}{|l|l|l|l|l|l|}
\hline Gender & \multicolumn{2}{|l|}{ Sexuality } & Raw p-value & $\begin{array}{l}\text { Unadjusted } \\
\text { alpha }(\mathbf{p}<\mathbf{0 . 0 5})\end{array}$ & $\begin{array}{l}\text { Bonferroni alpha } \\
(\mathbf{p}<\mathbf{0 . 0 1})\end{array}$ \\
\hline \multirow{3}{*}{ Women } & Bisexual & Lesbian & 0.007 & $* *$ & $*$ \\
\cline { 2 - 7 } & Bisexual & Straight & 0.875 & & \\
\cline { 2 - 7 } & Lesbian & Straight & 0.005 & $* *$ & $*$ \\
\hline \multirow{2}{*}{ Men } & Bisexual & Gay & 0.550 & & \\
\cline { 2 - 6 } & Bisexual & Straight & 0.921 & & \\
\cline { 2 - 6 } & Gay & Straight & 0.510 & & \\
\hline
\end{tabular}

Table 3. COG within-gender cross-sexuality pairwise comparisons

Comparing within sexuality but across gender (Table 4), the significant difference between bisexual women and men was lost after the correction. However, a significant difference between straight women and men maintained before and after the correction, such that straight women produced /s/ with a higher COG compared to straight men. This result is not surprising, given findings in previous literature on COG and gender difference (e.g., Munson et al. 2006b).

\begin{tabular}{|l|l|l|l|l|}
\hline \multicolumn{2}{|l|}{ Group } & Raw p-value & $\begin{array}{l}\text { Unadjusted alpha } \\
(\mathbf{p}<\mathbf{0 . 0 5})\end{array}$ & $\begin{array}{l}\text { Bonferroni alpha } \\
(\mathbf{p}<\mathbf{0 . 0 1})\end{array}$ \\
\hline $\begin{array}{l}\text { Bisexual } \\
\text { women }\end{array}$ & $\begin{array}{l}\text { Bisexual } \\
\text { men }\end{array}$ & 0.026 & $*$ & \\
\hline $\begin{array}{l}\text { Lesbian } \\
\text { women }\end{array}$ & $\begin{array}{l}\text { Gay } \\
\text { men }\end{array}$ & 0.529 & & $*$ \\
\hline $\begin{array}{l}\text { Straight } \\
\text { women }\end{array}$ & $\begin{array}{l}\text { Straight } \\
\text { men }\end{array}$ & 0.004 & $* *$ & \\
\hline
\end{tabular}

Table 4. COG within-sexuality cross-gender pairwise comparisons

4.3. SKEW MODEL. Skew measurements $(n=372)$ were subjected to a linear mixed-effects regression model. The model selection process indicated that neither GENDER, SEXUALITY nor 
their interaction contributed to the overall fit of the model. The random effects SPEAKER and WORD accounted for about $58 \%$ of the variance in the data, with SPEAKER explaining 43 times more variance than WORD. These results are surprising, given that previous studies such as the work by Munson and colleagues $(2006 \mathrm{a}, \mathrm{b})$ have found relatively strong evidence for differences in skew, especially between gay and straight men. Measures of central tendency and dispersion, however, suggest that the gay men in this sample produced /s/ with smaller skew values than straight men, which aligns with previous research (Munson et al. 2006a,b) (Figure 2).

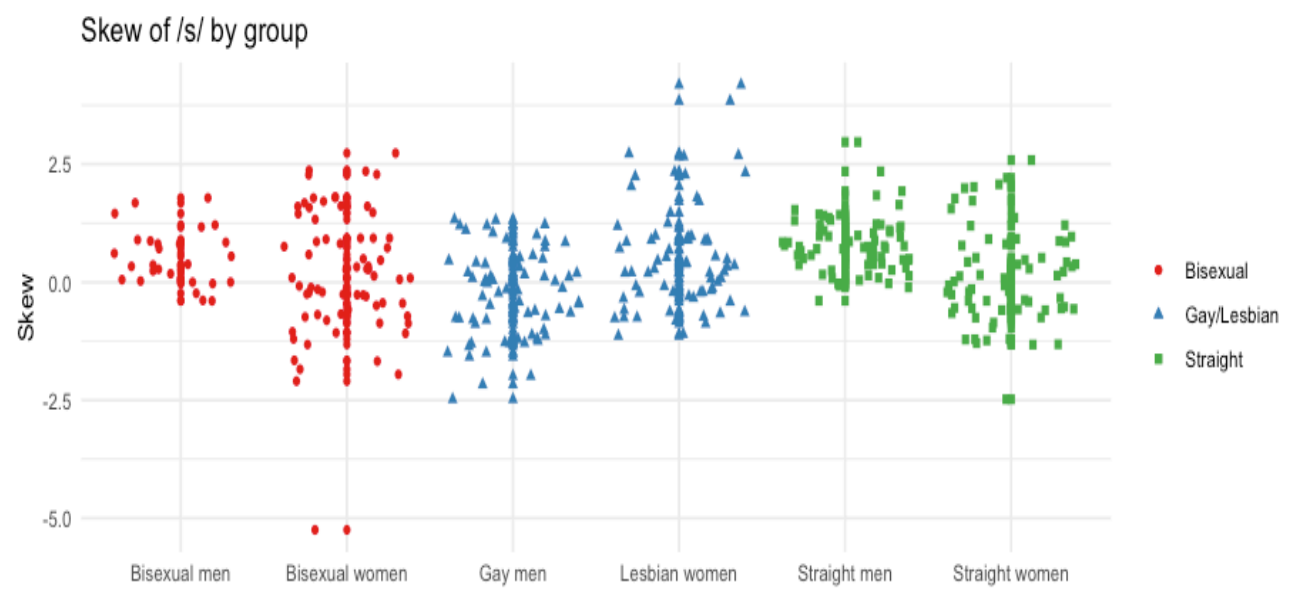

Figure 2. Distribution of skew by group

I posit a few plausible explanations for these unexpected results. The first is concerned with statistical methodologies. Over the years, a variety of modeling approaches have been used in sociophonetic studies of sexuality and the voice-MANOVA (e.g., Pierrehumbert et al. 2004, Munson et al. 2006a), ANOVA (e.g., Munson et al. 2006b, Zimman 2013), and regression models (e.g., Campbell-Kibler 2011, Zimman 2017) to name a few. Perhaps, then, inconsistent results between studies are artefacts of different methodological choices. Another possibility is that different speakers use distinct combinations of features to index sexuality and this particular set of speakers happens to not employ skew (Zimman, 2013). Alternatively, this group of speakers may index sexuality through skew but the sample size is too small to detect an effect. Yet another explanation is couched in intersectionality theory. Considering that SPEAKER is the vastly more important of the two random effects, it is possible that the influence of some other axis of identity that is embedded within SPEAKER, such as race, ethnicity, or regional affiliation, is the key. I will return to the importance of intersectionality later in this paper, but suffice to say for now that more work on the intersection between gender, sexuality, and other axes of identity is needed (though see Campbell-Kibler 2011, Pharao et al. 2014, Podesva \& Van Hofwegen 2014, Mendoza 2020).

4.4. DURATION MODEL. Duration measurements $(n=372)$ were subjected to a linear mixedeffects regression model. The model selection process indicated that a model with just SEXUALITY was the best fit and that SEXUALITY was a significant main effect $\left(\boldsymbol{\chi}^{2}(1)=29.9\right.$, $\mathrm{p}<0.001)$. The main effect GENDER and the GENDER*SEXUALITY interaction were not significant and thus were excluded from the final model (Table 5). 


\begin{tabular}{|l|l|l|l|l|l|}
\hline Fixed effects & Estimate & Std. error & df & t value & $\operatorname{Pr}(>\mid \mathbf{t})$ \\
\hline $\begin{array}{l}\text { Intercept } \\
\text { (bisexual) }\end{array}$ & 0.0567 & 0.006 & 22.834 & 9.163 & $4.14 \mathrm{e}-09 * * *$ \\
\hline Sexuality:Lesbian/Gay & 0.012 & 0.005 & 23.971 & 2.433 & $0.023 *$ \\
\hline Sexuality:Straight & 0.0343 & 0.005 & 24.001 & 6.921 & $3.71 \mathrm{e}-07 * * *$ \\
\hline
\end{tabular}

Table 5. Duration model coefficients table

Bisexual speakers produced /s/ with the shortest estimated duration $(57 \mathrm{~ms})$, followed by lesbian and gay speakers $(69 \mathrm{~ms})$, with straight speakers producing the longest $/ \mathrm{s} /$ tokens $(91 \mathrm{~ms})$ (Figure 3, Table 5). The fixed effects accounted for about $24 \%$ of the variance $(\mathrm{R} 2 \mathrm{~m}=0.24)$ and the random effects SPEAKER and WORD accounted for about $45 \%$ of the variance $(\mathrm{R} 2 \mathrm{c}=$ $0.68)$.

\section{Sexuality effect plot}

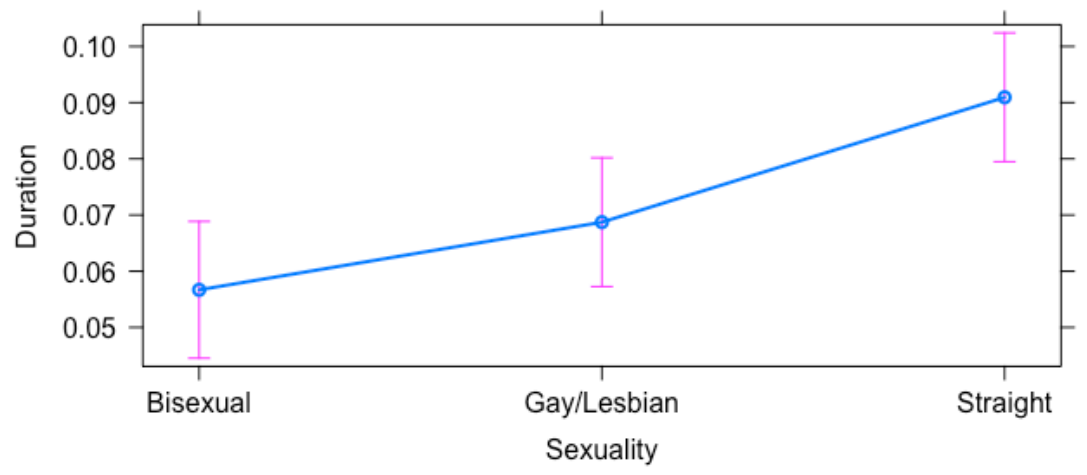

Figure 3. Duration model effects plot

WORD accounted for 3.5 times more variance than SPEAKER. As for possible confounds, I compared a model in which TOKEN was included as a random effect instead of WORD to investigate the influence of token position within the passage. TOKEN was represented as a factor with two more levels than WORD (14 levels versus 12 levels), as the words 'since' and 'size' were repeated twice in the passage. Model comparison with the anova function from base R indicated no significant difference between the two models. However, I did not control for global speech rate, which may have had an effect on the results.

4.5. DURATION POST-HOC PAIRWISE COMPARISONS. The model was releveled one time in order to examine the full set of pairwise comparisons for each group (two evaluations total). Significant differences were found between all three groups: bisexual speakers and lesbian/gay speakers $(\mathrm{p}<$ $0.05)$, bisexual speakers and straight speakers $(\mathrm{p}<0.001)$, as well as lesbian/gay speakers and straight speakers $(\mathrm{p}<0.001)$ (Table 6$)$. All differences maintained significance before and after the Bonferroni correction.

\begin{tabular}{|l|l|l|l|l|}
\hline \multicolumn{2}{|l|}{ Group Comparison } & Raw p-value & $\begin{array}{l}\text { Unadjusted alpha } \\
(\mathbf{p}<\mathbf{0 . 0 5})\end{array}$ & $\begin{array}{l}\text { Bonferroni alpha } \\
(\mathbf{p}<\mathbf{0 . 0 2 5})\end{array}$ \\
\hline Bisexual & Lesbian/Gay & 0.023 & $*$ & $*$ \\
\hline Bisexual & Straight & $3.71 \mathrm{e}-07$ & $* * *$ & $* * *$ \\
\hline Lesbian/Gay & Straight & $4.77 \mathrm{e}-05$ & $* * *$ & $* * *$ \\
\hline
\end{tabular}

Table 6. Duration post-hoc pairwise comparisons 
5. Qualitative analysis of post-test surveys. The post-test survey asked participants about the gender(s) to which they experience attraction as well as how they perceive themselves relative to gender stereotypes. I will focus on the gender stereotypicality section of the survey in this paper. Participants answered the questions "how stereotypically feminine do you consider yourself?" and "how stereotypically masculine do you consider yourself?" by selecting a number on a Likert scale in which 1 meant "not at all stereotypically feminine/masculine" and 7 meant "very stereotypically feminine/masculine". All but one participant provided ratings on both scales.

The straight participants often rated themselves towards the more extreme ends of the scales, in line with normative expectations for their gender (Table 7). All of the straight women rated themselves as more feminine than masculine. Likewise, all of the straight men rated themselves as more masculine than feminine. Lesbian women and gay men, however, rated themselves more towards the middle of the scale for both measures and did not systematically rate themselves as more feminine or masculine by group.

\begin{tabular}{|l|l|l|l|l|}
\hline Group & \multicolumn{2}{|l|}{ Femininity Rating } & \multicolumn{2}{l|}{ Masculinity Rating } \\
\hline & mean & range & mean & range \\
\hline Bisexual women & 5 & $3-6$ & 3 & $1-5$ \\
\hline Bisexual men & 4 & $3-5$ & 4 & $3-5$ \\
\hline Lesbian women & 4 & $3-5$ & 3 & $2-4$ \\
\hline Gay men & 3 & $2-5$ & 4 & $3-5$ \\
\hline Straight women & 6 & $5-7$ & 2 & $1-3$ \\
\hline Straight men & 2 & $1-3$ & 6 & $5-7$ \\
\hline
\end{tabular}

Table 7. Gender stereotypicality ratings by group

As for the bisexual participants, the two bisexual men who participated provided exactly opposite ratings: one bisexual man rated himself as more masculine (5) than feminine (3), while the other bisexual man rated himself as more feminine (5) than masculine (3). Most of the bisexual women rated themselves as more feminine (5-6) than masculine (1-2). However, one bisexual woman rated herself as more masculine (5) than feminine (3).

At this point, I will tentatively suggest that the bisexual men evaluated their gender stereotypicality in a way that is more similar to the gay men in this sample. I base this conclusion on the following: (1) neither the bisexual men nor the gay men systematically rated themselves as more feminine or more masculine as a group and (2) bisexual men's and gay men's ratings were both on the less extreme ends of the scales. In contrast, the majority of bisexual women evaluated their gender stereotypicality in a way that seems more similar to the straight women in this study. Four out of five bisexual women identified as more stereotypically feminine than masculine and provided ratings on the more extreme ends of the scales, similar to the straight women who participated. The one bisexual woman who judged herself as more masculine than feminine was just one of two in the whole sample to do so (the other being a lesbian woman).

6. Discussion. Before discussing the implications of these findings, I briefly summarize the key statistical results (Table 8). For center of gravity, bisexual women produced /s/ with a significantly higher center of gravity relative to lesbian women before and after the correction. Moreover, bisexual women produced /s/ with higher center of gravity relative to bisexual men, but this finding was no longer significant after the correction. No differences were found between bisexual women and straight women or among any of the groups of men. The skew model selection process indicated that neither GENDER, SEXUALITY, nor their interaction contribut- 
ed to the overall fit of the model. The random effect SPEAKER explained most of the variation. For duration, bisexual speakers produced shorter/s/ tokens than both lesbian and gay speakers and straight speakers before and after the correction, though these results could be confounded by global speech rate. In short, bisexual speakers do not consistently pattern with either lesbian, gay or straight speakers, or even with each other in the statistical models.

\begin{tabular}{|l|l|l|}
\hline Center of gravity & Skew & Duration \\
\hline $\begin{array}{l}\text { Significant difference between } \\
\text { bisexual and lesbian women } \\
\text { before and after correction }\end{array}$ & $\begin{array}{l}\text { No significant main effects } \\
\text { Most variation was explained } \\
\text { by random effect SPEAKER }\end{array}$ & $\begin{array}{l}\text { Significant differences be- } \\
\text { tween all three groups before } \\
\text { and after correction }\end{array}$ \\
$\begin{array}{l}\text { No difference between bisex- } \\
\text { ual and straight women }\end{array}$ & $\begin{array}{l}\text { Bisexual speakers' duration } \\
\text { was the shortest, followed by } \\
\text { lesbian/gay and then straight } \\
\text { speakers }\end{array}$ \\
$\begin{array}{l}\text { Significant difference between } \\
\text { bisexual women and men be- } \\
\text { fore correction only }\end{array}$ & $\begin{array}{l}\text { No difference between the } \\
\text { groups of men }\end{array}$ & \\
\hline
\end{tabular}

Table 8. Summary of key statistical results

The duration findings are particularly noteworthy in that the statistical model had the strongest evidence with respect to the Chi-squared values of the main effects and the p-values of the pairwise comparisons, yet the results contradict previous studies. Research on sexuality and duration has generally argued that increased duration is associated with sounding gay (e.g., Crist 1997, Linville 1998, Rogers, Smyth \& Jacobs 2000, but see Levon 2007 for an exception). However, the current study finds that lesbian and gay speakers produce /s/ with shorter duration than straight speakers, and that bisexual speakers produce /s/ with the shortest duration overall. Additional evidence is needed to explain why these results are inconsistent with earlier research and what exactly is being indexed by duration.

The qualitative analysis of the gender stereotypicality ratings complements the results of the statistical analyses in that consistent patterns did not arise between bisexuals and non-bisexuals, between bisexual women and bisexual men, or between members of the same gender-sexuality group. Although some of the bisexual women appear to pattern with straight women and there are some parallels between bisexual men's and gay men's ratings, bisexual speakers did not definitively pattern with any other group. Moreover, bisexual participants' gender stereotypicality ratings were not consistent among themselves. Most bisexual women rated themselves as more feminine than masculine, but one did not; the two bisexual men provided perfectly mirrored ratings, such that one identified as more feminine than masculine and the other identified as more masculine than feminine.

Taken together, the results of both the statistical and the qualitative analyses suggest that bisexual women and men experience gender, sexuality, and their intersection in distinct ways. How bisexual speakers orient to gender and sexuality vis-à-vis other axes of identity such as race is outside the scope of this paper, but the findings reported here provide empirical justification for the insights of intersectionality. In an intersectional framework, it is understood that different axes of identity interact in inextricable, non-additive ways (c.f. Crenshaw 1989). From this view, 
a plausible conclusion is that variation in /s/ production is not a matter of simply adding the effects of gender and sexuality (or other axes of identity) together for all measures in all contexts. Rather, one might expect various axes of identity to be foregrounded or downplayed in distinct ways between variables and between groups. That is, in fact, exactly what is reported herebisexual women and men pattern with each other in some respects and members of their gender in others and there are cases when their behavior is too complex to draw neat parallels. All in all, the complexity of these findings illustrates that bisexuality is not just a number on a Kinsey scale nor is it a straightforward amalgam of lesbianism/gayness or straightness; bisexuality is an identity in its own right that is worthy of empirical investigation.

In turn, these results have implications for the methodologies used in experimental sociophonetic studies of sexuality and the voice. The finding that bisexual speakers do not pattern consistently with lesbian and gay speakers in either the statistical models or the qualitative analysis casts doubt upon an a priori LGB category, underscoring the need for planned comparisons between these groups during initial data exploration. Put differently, bisexual speakers should occupy a distinct category unless there is empirical justification otherwise.

This study also has implications that extend beyond production studies to perception studies. Typically, sexuality judgements in perception studies are elicited using a binary forced-choice task (e.g., Smyth, Rogers \& Jacobs 2003) or an odd-point scale (e.g., Munson et al. 2006a). In the forced-choice paradigm, listeners are presented with a voice and asked to evaluate it as lesbian- or gay-sounding or as straight-sounding. This paradigm precludes the possibility of a voice sounding anything other than unambiguously lesbian, gay or straight and reinforces a binary understanding of sexuality. ${ }^{2}$ In the odd-point scale paradigm, listeners are asked to evaluate the sexuality of voices on a 5, 7, or 9-point Likert scale in which one end represents lesbian- or gaysounding and the other straight-sounding. This paradigm too renders unintelligible those voices that are not clearly lesbian-, gay-, or straight-sounding. It is not clear what, or rather who, the middle of a Likert scale represents nor is there any empirical reason to assume that all participants interpret these scales in the same way. The crux of this argument is not to undermine previous work on sexuality and the voice, which has been valuable in shedding light on monosexual identities. ${ }^{3}$ Rather, my intent is to highlight that binary ideologies of gender, sexuality, and normativity underlie some common experimental methodologies used in sociophonetic studies and that linguistic knowledge of sexuality and the voice loses nuance when these ideologies go uninterrogated. Attention to non-monosexual identities, such as bisexuality, extends the theorization of sexuality and the voice beyond ideologies of lesbian, gay, and straight difference.

7. Conclusion. This study makes several contributions to research on sexuality and the voice. To begin with, the statistical results suggest that more work on duration is needed. Duration is relatively understudied in relation to gender and sexuality compared to center of gravity or skew, but the duration model reported here had the strongest evidence of variation in /s/. Moreover, the results of the statistical and qualitative analyses indicate that bisexual speakers do not pattern systematically with lesbian or gay speakers, calling into question the practice of grouping them together a priori. Finally, bisexual speakers did not pattern consistently as a group in the statistical or qualitative analyses. Taken together, these findings indicate that close attention to the role of ideology, normativity, and intersectionality is needed in order to provide stronger theoretical

\footnotetext{
${ }^{2}$ A binary approach may be appropriate depending on the research question. However, the choice to employ such a design should be measured and intentional.

${ }^{3}$ The term monosexual refers to people who experience romantic, sexual, or affectional desire for only one gender (LGBTQIA+ Glossary, n.d.).
} 
grounding in future studies of sexuality and the voice. As sociophonetic research becomes more inclusive, it is imperative that researchers render more transparent the assumptions embedded within experimental methodologies. Such transparency is not only a matter of rigor, but also of ethics.

\section{References}

Audacity Team. 2019. Audacity(R): Free Audio Editor and Recorder, Version 2.3.2 [Computer program]. https://audacityteam.org/.

Barron-Lutzross, Auburn. 2015. The production and perception of a lesbian speech style. UC Berkeley Phonology Lab Report 11(11). https://escholarship.org/uc/item/7f6332bh.

Boersma, Paul. 2011. Praat: doing phonetics by computer [Computer program]. http://www.praat.org/.

Campbell-Kibler, Kathryn. 2011. Intersecting variables and perceived sexual orientation in men. American Speech 86(1). 52-68. https://doi.org/10.1215/00031283-1277510.

Crenshaw, Kimberlé. 1989. Demarginalizing the intersection of race and sex: A Black feminist critique of antidiscrimination doctrine, feminist theory and antiracist politics. University of Chicago Legal Forum. Article 8. https://chicagounbound.uchicago.edu/uclf/vol1989/iss1/8.

Crist, Sean. 1997. Duration of onset consonants in gay male stereotyped speech. University of Pennsylvania Working Papers in Linguistics 4(3). 4. http://repository.upenn.edu/pwpl/vol4/iss3/4.

Fairbanks, Grant. 1960. Voice and articulation drillbook. New York: Harper \& Row. https://doi.org/10.1288/00005537-194112000-00007.

Gaudio, Rudolf P. 1994. Sounding gay: Pitch properties in the speech of gay and straight men. American speech 69(1). 30-57. https://doi.org/10.2307/455948.

Hazenberg, Evan. 2016. Walking the straight and narrow: Linguistic choice and gendered presentation. Gender and Language 10(2). 270-294. https://doi.org/10.1017/S0047404500012756.

Lee, Sangseok \& Dong Kyu Lee. 2018. What is the proper way to apply the multiple comparison test? Korean Journal of Anesthesiology 71(5). 353-360. https://doi.org/10.4097/kja.d.18.00242.

Levon, Erez. 2006. Hearing "gay": Prosody, interpretation, and the affective judgements of men's speech. American Speech 8(1). 56-78. https://doi.org/10.1215/00031283-2006-003.

Levon, Erez. 2007. Sexuality in context: Variation and the sociolinguistic perception of identity. Language in Society 36(4). 533-544. https://doi.org/10.1017/S0047404507070431. Levon,

Erez. 2011. Teasing apart to bring together: Gender and sexuality in variations research. American Speech, 86(1). 69-84. https://doi.org/10.1215/00031283-1277519.

LGBTQIA+ Glossary. n.d. http://rcsgd.sa.ucsb.edu/education/lgbtqia-glossary (February 5, 2021).

Linville, Sue Ellen. 1998. Acoustic correlates of perceived versus actual sexual orientation in men's speech. Folia Phoniatrica et Logopaedica, 50(1). 35-48. https://doi.org/10.1159/000021447.

Mendoza, Christopher. 2021. That/s/tiene tumbao: Exploring the bilingual dimensions of [s+] production in Miami Latinx Drag. Paper presented at the Linguistic Society of America's $95^{\text {th }}$ Annual Meeting. 
Munson, Benjamin, Sarah V. Jefferson \& Elizabeth C. McDonald. 2006b. The influence of perceived sexual orientation on fricative identification. The Journal of the Acoustical Society of America 119. 2427-2437. https://doi.org/10.1121/1.2173521.

Munson, Benjamin, Elizabeth C. McDonald, Nancy L. DeBoe \& Aubrey R. White. 2006a. The acoustic and perceptual bases of judgements of women and men's sexual orientation from read speech. Journal of Phonetics, 34. 202-240. https://doi.org/10.1016/j.wocn.2005.05.003.

Pharao, Nicolai, Marie Maegaard, Janus Spindler Møller \& Tore Kristiansen. 2014. Indexical meaning of $\left[\mathrm{s}^{+}\right]$among Copenhagen youth: Social perception of a phonetic variant in different prosodic contexts. Language in Society 43. 1-31. https://doi.org/10.1017/S0047404513000857.

Pierrehumbert, Janet B., Tessa Bent, Benjamin Munson, Ann R. Bradlow \& J. Michael Bailey. 2004. The influence of sexual orientation on vowel production (L). The Journal of the Acoustical Society of America 116(4). 1905-1908. https://doi.org/10.1121/1.1788729.

Podesva, Robert \& Janneke Van Hofwegen. 2014. How conservatism and normative gender constrain variation in inland California: The Case of /s/. University of Pennsylvania Working Papers in Linguistics 20(2). Article 15.

https://repository.upenn.edu/pwpl/vol20/iss2/15.

Rogers, Henry, Ron Smyth \& Greg Jacobs. 2000. Vowel and sibilant duration in gay-andstraight-sounding male speech. Paper presented at the First International Gender and Language Association Conference (IGALA 1). Stanford, California, May 5-7.

R Core Team. 2019. R: A language and environment for statistical computing. Vienna, Austria: R Foundation for Statistical Computing. https:/www.R-project.org/.

Rendall, Drew, Paul L. Vasey \& Jared McKenzie. 2008. The Queen's English: An alternative, biosocial hypothesis for the distinctive features of "gay speech". Archives of sexual behavior 37(1). 188-204. https://doi.org/10.1007/s10508-007-9269-x.

Rothauser, E.H. 1969. IEEE recommended practice for speech quality measurements. IEEE Transactions on Audio and Electroacoustics 17. 225-246. https://doi.org/10.1109/TAU.1969.1162058.

Shapiro, Michael. 1995. A case of distant assimilation: /str/ $\rightarrow / \mathrm{ftr} /$. American Speech 70(1). 101-107. https://doi.org/10.2307/455876.

Smyth, Ron, Greg Jacobs, \& Henry Rogers. 2003. Male voices and perceived sexual orientation: An experimental and theoretical approach. Language in Society 32(3). 329-350. https://doi.org/10.1017/S0047404503323024.

Thorne, Lisa. 2013. "But I'm attracted to women": Sexuality and sexual identity performance in interactional discourse among bisexual students. Journal of Language and Sexuality 2(1). 70-100. https://doi.org/10.1075/j1s.2.1.03tho.

Van Borsel, John, Jana Vandaela \& Paul Corthals. 2013. Pitch and pitch variation in lesbian women. Journal of Voice 27(5). 656-713. https://doi.org/10.1016/j.jvoice.2013.04.008.

Waskler, Rachelle. 2001. Pitch range and women's sexual orientation. Word 52(1). 69-77. https://doi.org/10.1080/00437956.2001.11432508.

Zimman, Lal. 2013. Hegemonic masculinity and the variability of gay-sounding speech: The perceived sexuality of transgender men. Journal of Language and Sexuality 2(1). 1-39. https://doi.org/10.1075/j1s.2.1.01zim.

Zimman, Lal. 2017. Variability in /s/ among transgender speakers: Evidence for a socially grounded account of gender and sibilants. Linguistics 55(5). 993-1019. https://doi.org/10.1515/ling-2017-0018. 